\title{
Novas espécies e notas sinonímicas em Xystochroma Schmidt, 1924 (Coleoptera, Cerambycidae, Callichromatini)
}

\author{
Dilma Solange Napp ${ }^{1,3} \&$ Ubirajara R. Martins ${ }^{2,3}$
}

\begin{abstract}
${ }^{1}$ Departamento de Zoologia, Universidade Federal do Paraná. Caixa Postal 19020, 81531-980 Curitiba-PR, Brasil. ${ }^{2}$ Museu de Zoologia, Universidade de São Paulo. Caixa Postal 42494, 04218-970 São Paulo-SP, Brasil. ${ }^{3}$ Pesquisador do CNPq.
\end{abstract}

\begin{abstract}
New species and synonymical notes on Xystochroma Schmidt, 1924 (Coleoptera, Cerambycidae, Callichromatini). New synonyms established: X. neglectum (Gounelle, 1911) = Callichroma (Xystochroma) equestriforme Schmidt, 1924 syn. nov.; X. graclipes (Bates, 1879) = Callichroma (Xystochroma) planipenne Schmidt, 1924 syn. nov. = Callichroma (Xystochroma) cuprisuturatum Zajciw, 1965 syn. nov. New species described from Brazil: X. femoratum sp. nov., from Minas Gerais and Rio Grande do Sul; X. echinatum sp. nov. from Rio de Janeiro and São Paulo; from Venezuela: X. incomptum sp. nov., from Amazonas. A key to the species of Xystochroma is provided.

KEYWORDS. Cerambycinae; new species; new synonyms; South-America; Xystochroma.

RESUMO. Novas espécies e notas sinonímicas em Xystochroma Schmidt, 1924 (Coleoptera, Cerambycidae, Callichromatini). Novas sinonímias propostas: X. neglectum $($ Gounelle, 1911) = Callichroma $($ Xystochroma) equestriforme Schmidt, 1924 syn. nov.; X. gracilipes $($ Bates, 1879) = Callichroma (Xystochroma) planipenne Schmidt, 1924 syn. nov. = Callichroma (Xystochroma) cuprisuturatum Zajciw, 1965 syn. nov. Novas espécies descritas do Brasil: X. femoratum sp. nov. (Minas Gerais e Rio Grande do Sul); X. echinatum sp. nov. (Rio de Janeiro e São Paulo); da Venezuela: $X$. incomptum sp. nov. (Amazonas). Chave para identificação das espécies de Xystochroma é fornecida.
\end{abstract}

PALAVRAS-CHAVE. América do Sul; Cerambycinae; espécies novas; novos sinônimos; Xystochroma.

Doze espécies foram catalogadas no gênero Xystochroma por Monné (1993) e apenas uma, X. buprestoides (Bates, 1865) não ocorre na América do Sul. Neste trabalho três espécies novas são descritas e três nomes considerados como sinônimos, portanto, o número de espécies permanece inalterado. X. equestriforme (Schmidt, 1924) não foi examinada; X. clypeatum (Schwarzer, 1923) e X. planipenne (Schmidt, 1924) foram estudadas através dos diapositivos dos tipos.

O material examinado pertence às seguintes instituições: DZUP, Departamento de Zoologia, Universidade Federal do Paraná, Curitiba; MCNZ, Museu de Ciências Naturais, Fundação Zoobotânica do Rio Grande do Sul, Porto Alegre; MNRJ, Museu Nacional, Universidade Federal do Rio de Janeiro, Rio de Janeiro; MZSP, Museu de Zoologia, Universidade de São Paulo, São Paulo; SMFD, Forschungsinstitut und Naturmuseum Senckenberg, Frankfurt-am-Main.

Xystochroma Schmidt, 1924

Callichroma (Xystochroma) Schmidt, 1924: 299.

Xystochroma; Podany, 1965: 38; Monné, 1993: 8 (cat.).

Espécie-tipo: Callichroma neglectum Gounelle, 1911, designação original.

Genas mais curtas do que o maior diâmetro do lobo ocular inferior. Tubérculos anteníferos pouco elevados, arredondados. Antenas dos machos ultrapassam os ápices elitrais, no máximo, em 1,5 artículos; nas fêmeas, pouco mais curtas que o corpo. Escapo subcilíndrico, sem depressão no lado dorsal da base e projeção apical praticamente nula; antenômeros IV-X expandidos no ápice externo; antenômero XI, nos machos, pouco mais longo que o X; nas fêmeas, tão ou pouco mais longo que o $\mathrm{X}$.

Protórax transverso. Tubérculos laterais desenvolvidos. Élitros com faixa sutural, verde ou azulado-metálica, distinta; faixa dorsal de cor metálica evidente ou não. Superfície elitral revestida por tomento negro organizado, ou não, em faixa dorsal.

Metafêmures cilíndricos; nos machos alcançam ou apenas ultrapassam as pontas dos élitros; nas fêmeas, não chegam a atingi-las. Metatíbias sem carena, deprimidas e pouco alargadas para o ápice. Metatarsômero I mais longo que II+III.

Discussão. Dentre os gêneros sul-americanos de Callichromatini com fêmures cilíndricos, Xystochroma assemelha-se a Xenochroma Schmidt, 1924 e Mionochroma Schmidt, 1924. Difere do primeiro por apresentar faixas de colorido metálico nos élitros e pelos tubérculos nos lados do protórax bem desenvolvidos. De Mionochroma, pelas antenas curtas em ambos os sexos (nos machos ultrapassam os ápices elitrais, no máximo por 1-1,5 artículos e, nas fêmeas, no máximo, alcançam os ápices), pelos antenômeros IV-X expandidos nos ápices externos e pelo escapo sem depressão dorso-basal.

Em Xenochroma, os élitros são unicolores (exceto $X$. seabrai Fragoso \& Monné, 1989) e os tubérculos laterais do 
protórax são pouco desenvolvidos. Em Mionochroma, as antenas, nos dois sexos, são mais longas que o corpo, os antenômeros são cilíndricos e o escapo, usualmente, apresenta depressão no lado dorsal da base.

O gênero Linsleychroma Giesbert, 1998, descrito do Panamá, para L. monnei Giesbert, 1998, não examinada, também parece assemelhar-se a Xystochroma. As distinções, segundo Giesbert (1998), resumem-se a: "hind femora somewhat flattened laterally, strongly sulcate and carinate on inner side beneath". Espécies de Xystochroma não têm sulco ladeado por carenas no lado inferior e talvez este possa ser mais um caráter para distinguir Xystochroma de Linsleychroma.

Chave para espécies de Xystochroma (exceto X. buprestoides)

1. Pro- e mesofêmures inteiramente negros ou com colorido metálico

Pro- e mesofêmures alaranjados ou alaranjados e pretos

2(1).Faixa sutural dos élitros larga, nítida e de pubescência dourada; fêmures negros; metafêmures com pêlos curtos, rijos, na face ventral do quarto apical. Colômbia X. setigerum (Schmidt, 1924)

Faixa sutural dos élitros estreita e metálica . .3

3(2). Fêmures com brilho metálico, verde ou azul; antenas dos machos ultrapassam os ápices dos élitros em 1,5 artículos; pronoto, na metade anterior, com pequena área triangular brilhante, restante da superfície fina e uniformemente pontuada. Panamá, Colômbia, Venezuela X. chloropus (Bates, 1879)

Fêmures pretos; antenas dos machos (e das fêmeas) apenas ultrapassam os élitros; linha média do pronoto brilhante, com ou sem rugas transversais; (clípeo com rugas transversais). Costa Rica, Panamá, Venezuela X. clypeatum (Schwarzer, 1923)

4(1). Metafêmures inteiramente alaranjados ou alaranjados com o extremo apical preto em pequena extensão .... 5

Metafêmures alaranjados com, pelo menos, o terço apical preto ou com brilho metálico

5(4). Lado interno dos metafêmures com carena no quarto apical (Fig. 4)

Metafêmures sem carena

6(5). Faixa sutural estreita; tubérculos laterais do protórax aguçados; disco do pronoto sem rugas; antenômero III sem carena. (Figs. 1, 4). Brasil (Minas Gerais, Rio Grande do Sul) $X$. femoratum sp. nov.

Faixa sutural larga; tubérculos laterais do protórax rombos; disco do pronoto com rugas transversais; antenômero III carenado. (Fig. 2). Venezuela

X. incomptum sp. nov.

7(5). Faixa central do pronoto sem rugas; faixa sutural dos élitros recoberta por pêlos amarelados. Brasil (Rio de Janeiro ao Rio Grande do Sul, Goiás) .....

X.neglectum (Gounelle, 1911)

Faixa central do pronoto com rugas transversais; faixa sutural dos élitros glabra, sem pêlos amarelados. Brasil (Distrito Federal, Rio de Janeiro, São Paulo, Paraná, Santa Catarina) X. bouvieri (Gounelle, 1911)

8(4). Lado inferior do terço apical dos metafêmures com cerdas rijas, com ápice dirigido para a ponta do fêmur e inseridas em projeções agudas (Fig. 5); (faixa sutural dos élitros larga, ultrapassa sensivelmente os lados do friso sutural, revestida por pilosidade amarelada, melhor visível quando a cabeça voltada para a fonte luminosa). (Fig. 3). Brasil (Rio de Janeiro, São Paulo)

X. echinatum sp. nov.

Lado inferior dos metafêmures com pêlos curtos e não inseridos em projeções

9

9(8). Escapo cilíndrico, sem dilatação apical; pontuação na face dorsal fina e densa. Antenômero III cilíndrico, sem carena e densamente piloso. 10

Escapo com ângulo apical externo levemente projetado; pontuação da face dorsal rala e irregular. Antenômero III com carena e esparsamente pubescente. Brasil (Rio de Janeiro, São Paulo) .............. . zikani (Zajciw, 1965)

10(9).Faixa sutural geralmente muito indistinta; metafêmures delgados, achatados e com reflexo metálico no ápice. Brasil (Goiás, Minas Gerais, Rio de Janeiro, São Paulo, Paraná). X. gracilipes (Bates, 1879)

Faixa sutural, embora estreita, evidente; metafêmures cilíndricos, com ápice preto. Brasil (Rio de Janeiro: Corcovado) ............................ X. minutum (Zajciw, 1965)

Xystochroma neglectum (Gounelle, 1911)

Callichroma neglectum Gounelle, 1911: 172, 2 figs.

Callichroma (Xystochroma) neglectum; Schmidt, 1924: 301; Demets, 1973: 173 (syn.)

Xystochroma neglectum; Podany, 1965: 39; Monné, 1993: 9 (cat.). Xystochroma roeri Podany, 1965: 35, fig. 1.

Callichroma (Xystochroma) equestriforme Schmidt, 1924: 302. Syn. nov.

Xystochroma equestriforme; Podany, 1965: 39; Monné, 1933: 9 (cat.).

Não foram detectados caracteres para diferenciar $X$. equestriforme (Schmidt, 1924) de X. neglectum (Gounelle, 1911), embora o holótipo de X. equestriforme, descrita do Brasil, sem localidade precisa, não tenha sido examinado.

Gounelle (1911) baseou a descrição de X. neglectum em 14 síntipos procedentes de Goiás (Jataí), Rio de Janeiro (Rio de Janeiro: Tijuca, Bico do Papagaio) e São Paulo (Ribeirão Pires).

Villiers (1972: 21) citou, para X. neglectum, um "holótipo", procedente do Rio de Janeiro (Tijuca), e "parátipos", mas essa indicação é inválida porque deveriam ter sido indicados lectótipo e paralectótipos. 

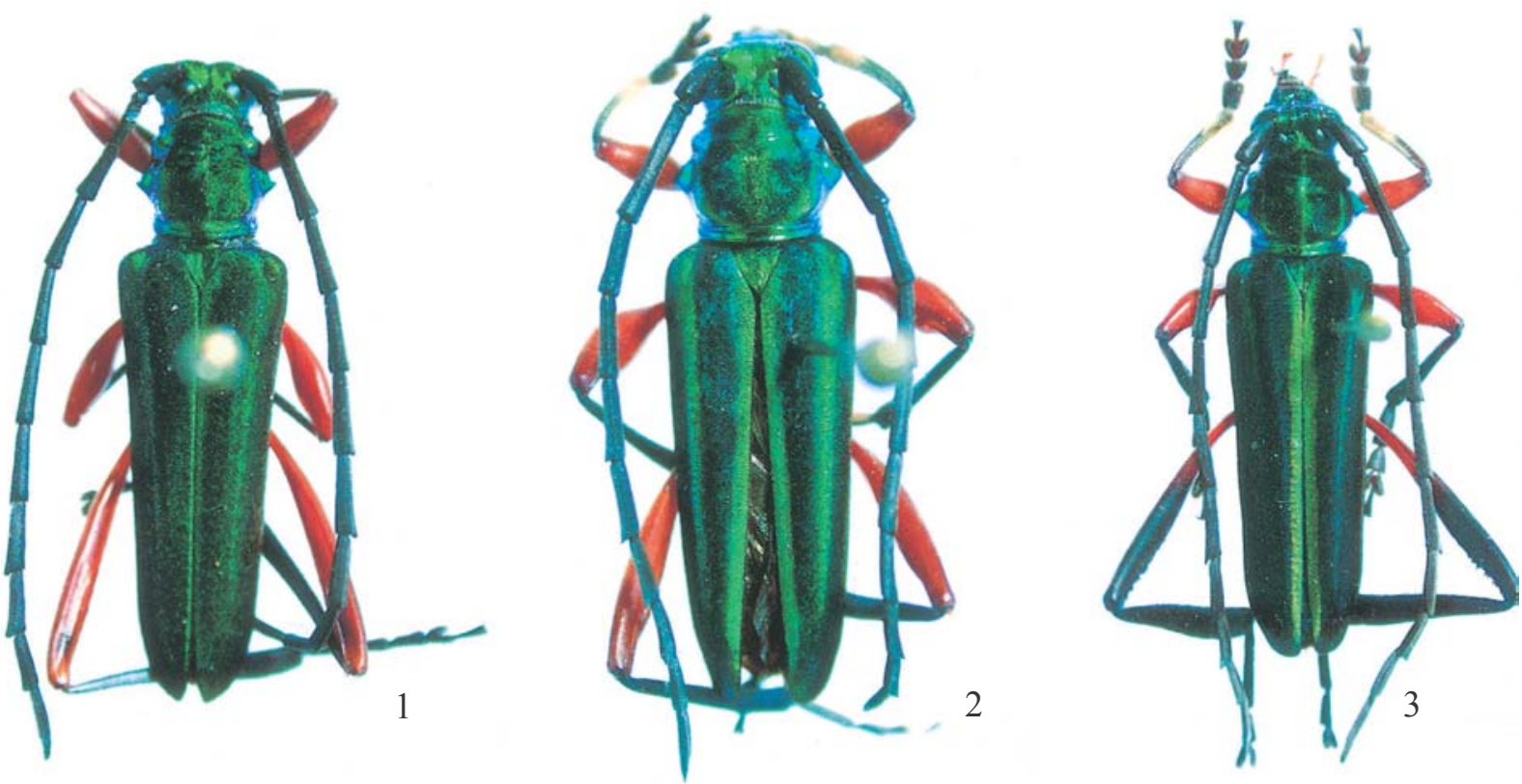

Figs. 1-3. 1, Xystochroma femoratum sp. nov., holótipo macho; 2, X. incomptum sp. nov., holótipo macho; 3 , X. echinatum sp. nov., holótipo macho.
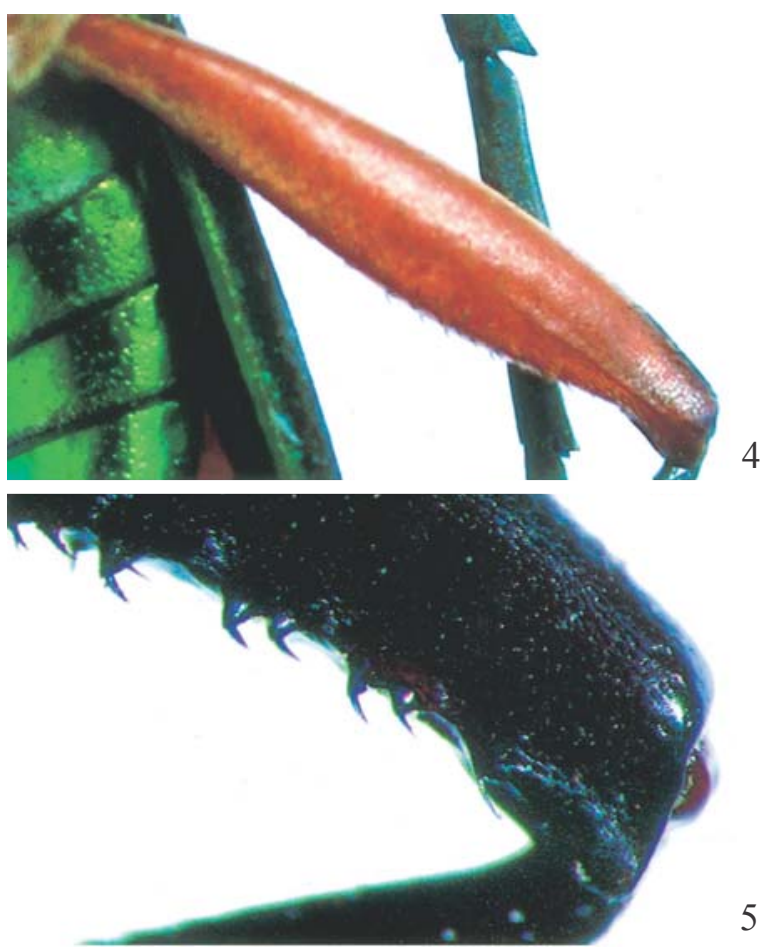

5

Figs. 4-5. 4, Xystochroma femoratum, detalhe do metafêmur; 5, X. echinatum, idem.

Zajciw (1958) arrolou X. equestriforme para o Rio de Janeiro (Corcovado) com base num macho, examinado, o que permitiu confirmar a sinonímia proposta.

Além do material mencionado abaixo, foram examinados seis exemplares de $X$. neglectum comparados com o "tipo" do
MNHN por Y. Demets, todos procedentes do Rio de Janeiro (MZSP, DZUP).

Material examinado. BRASIL. Distrito Federal: Taguatinga, macho, 14.I.1984, J. Dalmacio col. (MZSP). Rio de Janeiro: Rio de Janeiro, 2 machos, fêmea, 1910, Dupuis col. (MZSP); fêmea, 21XI.1918, sem nome do coletor (MZSP); (Corcovado), macho, 23.I.1952, macho, 7.XII.1952, macho, 29.XI.1953, D. Zajciw col., macho, I.1969, S. A. Fragoso col. (MNRJ); (Represa Rio Grande), fêmea, 27.IX.1967, F. Oliveira col. (DZUP); (Santa Teresa), macho, XII.1917, nome de coletor ilegível (MZSP); (Silvestre), fêmea, 28.XII.1918, sem nome do coletor; Petrópolis (Independência, 900 m), fêmea, 17.XII.37, Gagarin col. (MZSP); Seropédica ( $\mathrm{km} 47$ da antiga rodovia Rio-São Paulo), fêmea, 8.II.1943, O. Braga col. (MZSP). São Paulo: Guarujá, fêmea, XII.1928, nome do coletor ilegível; São Bernardo, fêmea, 28.III.1923, R. Spitz col. (MZSP). Paraná: Guarapuava, macho, XI.1970, Schneider col. (MZSP). Santa Catarina: Joinville, fêmea, I.1922, Schmith col. (MZSP). Rio Grande do Sul: Nova Petrópolis, fêmea, XI.1940, sem nome do coletor (MZSP).

\section{Xystochroma gracilipes (Bates, 1879)}

Callichroma gracilipes Bates, 1879: 404.

Xystochroma gracilipes; Podany, 1965: 39; Monné, 1993: 9 (cat.). Callichroma (Xystochroma) planipenne Schmidt, 1924: 303. Syn. nov.

Xystochroma planipenne; Podany, 1965: 39; Monné, 1993: 9 (cat.). Callichroma (Xystochroma) cuprisuturatum Zajciw, 1965: 552, fig. 2. Syn. nov.

Xystochroma cuprisuturatum; Monné, 1993: 9 (cat.).

De Callichroma gracilipes Bates, 1879 foi examinado diapositivo do holótipo fêmea (MNHN) e material comparado com esse exemplar por Y. Demets (MZSP). De Callichroma (Xystochroma) planipenne Schmidt (1924), o diapositivo do holótipo fêmea do SMFD, enviado por K.-E.Huedepohl, e de Callichroma (Xystochroma) cuprisuturatum Zajciw, 1965, 
parátipo fêmea (MNRJ). Concluímos que todos esses nomes foram atribuídos a única espécie.

Material examinado. BRASIL. Goiás: Jataí, macho (MZSP); fêmea, ex-Coleção Le Moult (MZSP). Minas Gerais: Lavras, fêmea, IV.1937, P. J. Ribeiro col. (MZSP); Passa Quatro (Fazenda dos Campos), macho, 18.XI.1915, J. F. Zikán col. (MZSP). São Paulo: Botucatu, macho, 5.VI.1966, A. Mantovan col. (MZSP). Campos do Jordão, fêmea, 20.I.1936, J. Lane col. (MZSP); 4 machos, I.1954, J. Lane col. (MZSP); Guarujá, macho, 2.IX.1928, Mieln col. (MZSP); Peruíbe, fêmea, 7.XI.1950, Col. H. Zellibor, parátipo de C. (X.) cuprisuturatum (MNRJ); São Paulo (Butantã), fêmea, 21.V.1941, A. T. Mendes col.; (Cantareira), macho, IV.1931, R. Spitz col. (MZSP); (Ipiranga), fêmea, VII.1917, sem nome do coletor (MZSP); (Santo Amaro), macho, 13.III.1921, J. Melzer col. (MZSP); macho, VI.1932, J. Lane col. (MZSP).

\section{Xystochroma femoratum sp. nov.}

(Figs. 1, 4)

Cabeça, protórax, élitros e face ventral, verde-metálicos. Antenas, tíbias e tarsos, pretos. Fêmures alaranjados. Clípeo e genas brilhantes com pontuação esparsa. Fronte, vértice e occipício com pontuação muito fina e densa. Antenas dos machos atingem os ápices dos élitros na metade do antenômero XI; das fêmeas, aproximam-se, mas não atingem as pontas dos élitros. Escapo subcilíndrico com aba apical externa apenas projetada; pontuação fina e densa; nas fêmeas com meio do dorso ligeiramente mais avermelhado. Antenômero III não carenado. Antenômero XI apendiculado nos machos, mais longo que o X e nas fêmeas, apenas mais curto.

Tubérculo lateral do protórax desenvolvido, aguçado na ponta. Pronoto finamente pontuado no disco; nos lados, com rugas transversais espaçadas até o tubérculo lateral. Partes laterais do protórax e tubérculos laterais praticamente lisos e brilhantes. Pubescência pronotal preta e não constitui faixas.

Escutelo sulcado, fina e densamente pontuado. Élitros com estreita faixa sutural verde-metálica; faixa dorsal visível apenas conforme a incidência da luz e, na realidade, toda a superfície elitral é verde-metálica sob a pilosidade.

Mesofêmures com carena muito discreta no lado interno do ápice. Metafêmures lineares; ápices apenas ultrapassam as pontas dos élitros nos machos e nas fêmeas, não chegam a atingi-las; face interna com carena evidente no quarto apical; face externa com depressão apical e no lado inferior dessa depressão discretamente carenada. Metatíbias deprimidas com metade distal mais larga e sinuosa. Metatarsômero I mais longo do que II+III reunidos.

Dimensões em mm, respectivamente, macho/fêmea. Comprimento total, 16,2/17,0; comprimento do protórax, 3,1/ 3,1 ; maior largura do protórax, 3,7/3,8; comprimento do élitro, $11,9 / 12,9$; largura umeral, 4,3/4,4.

Holótipo macho procedente do BRASIL, Rio Grande do Sul: Porto Alegre, 1926, P. Buck col. (MZSP). Parátipo fêmea: BRASIL, Minas Gerais: Coronel Pacheco, sem outros dados (MZSP).

Discussão. Xystochroma femoratum sp. nov. e $X$. incomptum sp. nov. são as espécies do gênero que apresentam carena na face interna dos ápices dos metafêmures (Fig. 4). $X$. femoratum difere de $X$. incomptum pelo antenômero III não carenado; centro-longitudinal do pronoto sem rugas; pelo tubérculo lateral do protórax aguçado; pelo escutelo sulcado e sem rugas, pelas faixas elitrais pouco visíveis e pelo tomento elitral que não constitui faixas longitudinais; fêmures, especialmente os posteriores, lineares e metatíbias sinuosas e alargadas para o ápice.

Em X. incomptum, o antenômero III é carenado; o centrolongitudinal do pronoto tem rugas; o tubérculo lateral do protórax é rombo; o escutelo não tem sulco e tem rugas na região apical; as faixas elitrais são evidentes; o tomento elitral constitui duas faixas longitudinais; os metafêmures são clavados e as metatíbias são retas e discretamente alargadas.

$\mathrm{O}$ epíteto é alusivo à carena nos metafêmures.

\section{Xystochroma incomptum sp. nov.} (Fig. 2)

Etimologia. Latim, incomptus $=$ sem adornos.

Cabeça, protórax, élitros e face ventral verde-metálicos. Antenas, tíbias e tarsos, pretos. Fêmures alaranjados com extremo basal preto. Clípeo com pontuação grossa. Fronte e vértice com pontuação finíssima e densa. Genas com pontuação fina e esparsa. Antenas (macho) atingem o ápice elitral na extremidade do antenômero X. Escapo subcilíndrico, sem projeção externa apical, fina e densamente pontuado. Antenômero III carenado. Antenômero XI mais longo que o $\mathrm{X}$, levemente apendiculado.

Tubérculo lateral do protórax desenvolvido, mas sem ponta acuminada. Pronoto com rugas transversais exceto nas áreas cobertas pelo tomento preto; sulco basal brilhante e glabro. Partes laterais do protórax lisas, mas pontuadas nos tubérculos medianos.

Escutelo sem sulco, finamente pontuado nos $2 / 3$ basais e com rugas na região apical. Élitros com faixas verde-metálicas, evidentes e glabras, uma sutural e uma dorsal; e duas faixas largas, dorsais de tomento.

Fêmures robustos; os mesofêmures fortemente pedunculados e clavados; metafêmures clavados, os ápices não alcançam as pontas dos élitros. Mesofêmures com carena curta (restrita ao quinto apical) e evidente nas faces laterais. Metafêmures com carena interna bem distinta no terço distal e carena externa pouco aparente. Metatíbias cilíndricas, pouco alargadas para o ápice e retilíneas. Metatarsômero I tão longo quanto II+III reunidos.

Dimensões em mm. Comprimento total, 14,9; comprimento do protórax, 3,1; maior largura do protórax, 3,8; comprimento do élitro, 10,5; largura umeral, 4,1.

Holótipo macho da VENEZUELA, Amazonas: Surumoni ("KRAN Tag: vd. Sapindaceae"), 26.IX.1997, Morawetz col. (MZSP). Os dados de etiqueta indicam: KRAN $=$ guindaste .

\section{Xystochroma echinatum sp. nov.}

(Figs. 3, 5)

Etimologia. Latim, echinatum $=$ espinhoso, alusivo à fileira de espinhos dos metafêmures. 
Cabeça, protórax e face ventral verde-metálicos. Antenas, tíbias e tarsos pretos. Élitros verde-metálicos com ligeiro brilho violáceo nas epipleuras. Pro- e mesofêmures alaranjados, com base enegrecida ou não, os ápices pretos; metafêmures com base alaranjada e $2 / 3$ ou quase a metade apical preta.

Clípeo com pontos grossos irregularmente adensados. Fronte fina e densamente pontuada. Genas com pontuação mais esparsa do que a fronte. Antenas do machos alcançam o ápice dos élitros na ponta do antenômero IX ou do X. Antenas das fêmeas tão longas ou pouco mais curtas que o corpo. Escapo sem projeção apical externa, fina e densamente pontuado. Antenômero III não carenado. Antenômero XI mais longo que o $\mathrm{X}$ e apendiculado.

Tubérculo lateral do protórax desenvolvido, aguçado na ponta. Pronoto fina e densamente pontuado, sem rugas e revestido por tomento. Na metade anterior do disco, faixa mediana, glabra e brilhante. Partes laterais do protórax com pontos finos e muito esparsos à frente e sobre o tubérculo lateral; a parte posterior e o sulco da base do pronoto lisos e brilhantes.

Escutelo com sulco estreito e mediano; finamente pontuado e revestido por tomento preto. Élitros com faixa sutural de pubescência dourada, estreitada atrás do escutelo.

Pro- e mesofêmures clavados. Metafêmures sublineares sem carena; nos machos atingem o ápice dos élitros; nas fêmeas, aproximam-se, mas não atingem as pontas; no quarto apical da face inferior com duas fileiras de espinhos curvos e situados sobre projeções (Fig. 5). Metatíbias praticamente retilíneas, não carenadas, deprimidas e alargadas para o ápice. Metatarsômero I mais longo que II+III.

Dimensões em mm, respectivamente, macho/fêmea. Comprimento total, 18,4-19,3/19,3-22,0; comprimento do protórax, 3,6-3,7/3,2-4,0; maior largura do protórax, 4,6-4,7/4,05,3; comprimento do élitro, 13,5-14,7/14,8-16,5; largura umeral, $4,8-5,2 / 4,7-5,9$.

Holótipo macho, BRASIL, Rio de Janeiro: Rio de Janeiro (Corcovado), 20.X.1959, Alvarenga \& Seabra col. (MNRJ). Parátipos - mesma localidade do holótipo, fêmea, 29.XI.1957, Seabra \& Alvarenga col. (MNRJ); fêmea, 23.X.1958, Alvarenga \& Seabra col. (MNRJ); fêmea, 17.XI.1958, Alvarenga \& Seabra col. (MNRJ); macho, XI.1960, C. A. Campos Seabra col. (MNRJ); 2 fêmeas, XI.1961, Alvarenga \& Seabra col. (MNRJ); fêmea, 27.XII.1962, Alvarenga \& Seabra col.
(MZSP); macho, 30.X.1963, Alvarenga \& Seabra col. (MNRJ); fêmea, 7.XI.1963, Alvarenga \& Seabra col. (MZSP); fêmea, 28.XI.1969, Alvarenga \& Seabra col. (DZUP); fêmea, XI.1970, C. A. C. Seabra col. (MNRJ); fêmea, 10.XI.1975, M. A. Monné \& C. A. C. Seabra col. (DZUP); fêmea, 3.XII.1976, M. A. Monné \& C. A. C. Seabra col. (MCNZ); fêmea, 18.XII.1980, C. A. C. Seabra col. (MNRJ). São Paulo: Bananal (Serra da Bocaina), macho, I.1937, D. Mendes col. (MZSP).

Discussão. Xystochroma echinatum sp. nov. separa-se de todas as outras espécies por apresentar duas fileiras de espinhos curvos no lado inferior do quarto distal dos metafêmures (Fig. 5).

Agradecimento. A Antonio Santos Silva (MZSP) pela execução das fotos que ilustram este artigo.

\section{REFERÊNCIAS}

Bates, H. W. 1879. New genera and species of Callichrominae (Coleoptera, Longicornia). Cistula Entomologica 2: 395-419.

Demets, Y. 1973. Notes sur les Callichromatini (Coleoptera, Cerambycidae). Papéis Avulsos de Zoologia 26: 173-177.

Giesbert, E. F 1998. Further Studies in the Neotropical Callichromatini (Coleoptera: Cerambycidae: Cerambycinae. Occasional Papers of the Consortium Coleopterorum 2: 60-64.

Gounelle, E. 1911. Liste des cérambycides de la région de Jathay, État de Goyaz, Brésil. Annales de la Société Entomologique de France 80: 103-252.

Monné, M. A. 1993. Catalogue of the Cerambycidae (Coleoptera) of the Western Hemisphere. Part VIII. São Paulo, Sociedade Brasileira de Entomologia, 97 p.

Podany, C. 1965. Remarques sur les Callichromini américains (Col., Ceramb.). Bulletin de la Société Entomologique de Mulhouse 1965: 34-41.

Schmidt, M. 1924. Die amerikanischen Callichrominen (Col., Ceramb.) nach systematischen und phylogenetischen Gesichtspunkten dargestellt. Deutche Entomologische Zeitschrift 1924: 297321.

Villiers, A. 1972. Les types de Cerambycidae Callichromini neotropicaux du Museum de Paris. Designation de lectotypes. Bulletin de la Société Entomologique de France 77: 20-22.

Zajciw, D. 1958. Fauna do Distrito Federal XLVIII. Contribuição para o estudo dos longicórneos do Rio de Janeiro. Boletim do Museu Nacional (nova série) Zoologia 189: 1-26.

Zajciw, D. 1965. Três espécies novas do gênero Callichroma Latreille, 1816, subgênero Xystochroma Schmidt, 1924 (Col., Cerambycidae, Cerambycinae). Anais da Academia Brasileira de Ciências 37: $551-555$ 